\section{The Fine Art of the Tongue}

Nancy Holroyde-Downing
In 1341 during the Yuan Dynasty, a medical text appeared which contained 36 drawn representations of a variety of tongues. Each was accompanied by an explanation of what the individual tongue image depicted in terms of illness, and a directive as to what prescription was necessary to treat that illness. The title of the text was the Aoshi shanghanjinjing lu 敖氏傷寒金鏡錄 (Scholar Ao's Golden Mirror of Cold Damage Disorders), and the provenance of these tongue images weaves a fascinating story.

The inspection of the tongue is now a pervasive aspect of a diagnosis, and it is a fundamental part of the curriculum in most colleges of Chinese medicine worldwide. It is discussed in diagrammatic and theoretical detail in contemporary Chinese medical textbooks and is a feature of the 'signs and symptoms' used in planning or discussing acupuncture and herbal medicine treatment. There are myriad tongue diagnosis teaching texts, most recently with photographic images of tongues in vast quantities showing great varieties of qualities. Tongue diagnosis is usually presented together with pulse diagnosis as systems having comparable antiquity and joint primacy in the clinical encounter. And yet, even a cursory look at classical texts, case histories and formularies from the Han (206 BCE-22O CE) to the Qing (1644-1912) dynasty suggests it has not always enjoyed its current status.

\section{A Brief Textual History}

It is, of course, impossible in this chapter to exhaustively address all the received texts of Chinese medicine that refer to the tongue. However, even a brief glance at a selection of references to the tongue from the Han through the Song Dynasties reveals two interesting facts. These references are neither expressions of a diagnostic system, nor are they conveyed as images.

Texts from the Mawangdui 馬王堆 burial site (closed 168 вCE) are thought to pre-date the classical compilations of Chinese acupuncture theory found in the Huangdineijing 黄帝内經 (Yellow Emperor's Inner Classic), ${ }^{1}$ and the

The Huangdi neijing corpus consists of two treatises: Suwen 素 問 (Fundamental Questions) and Lingshu靈樞 (The Numinous Pivot), written down $c$. 2nd century BCE, plus the $c$. 7 th-century CE Taisu太素 (Great Basis) recension, which overlaps with both. These texts are generally considered to contain the core theory
Nanjing 難經 (Classic of Difficult Issues). ${ }^{2}$ The Mawangdui tomb texts, reflecting the newly emerging physiological medicine of the Warring States and early Han, present early concepts of the body's vessel system. In these texts also, diseased bodies begin to be ascribed to a slow breakdown of a state of internal harmony, rather than to attacks by a displeased ancestor or spirit. Evidence of connection between the tongue and the body's organs is found in vessel descriptions such as: 'attached to the kidney, and presses laterally on the tongue', ${ }^{3}$ or 'emerges at the liver, enters the upper side, and is attached to the tongue'. ${ }^{4}$ The tongue also features in Yin yang mai sihou 陰陽脈死 侯 (Death Signs of the Yin and Yang Vessels), a text from Mawangdui concerned with the prognosis of death, which states: 'when the tongue binds and the testicles curl up, muscle has died first'. 5

By the time of the 'Jingmai' 經脈 treatise of the Lingshu recension of the Huangdi neijing, the anatomical planes of the vessels link clearly with organs and there is an elaborate system of correspondences in place that begins to systematise pulse and complexion diagnosis. Yet the Huangdineijing corpus contains only a handful of references to the tongue within the vessel/organ framework, and only scattered mentions of the tongue's colour or dryness.

The foundations of classical medicine were set out by the end of the Han dynasty. The Nanjing, often considered the work that represents 'the apex, and also the conclusion, of the developmental phase of the conceptual system known as the medicine of systematic correspondence, ${ }^{6}$ only makes passing references to the tongue. In it, we learn that the tongue weighs $283 \mathrm{~g}$, and has a length of $17.8 \mathrm{~cm}$ and a width of $6.4 \mathrm{~cm}$; that when cold and heat have affected the flesh, the lips and the tongue will dry out; that the influences of the heart pass through the tongue; that when the tongue is at ease, one knows the difference between the five tastes; and that when the Foot-Ceasing-Yin vessel is compromised, the testicles draw in and the tongue rolls back. ${ }^{7}$

of traditional Chinese medicine.

Probably compiled in the 1st or 2nd century CE.

Harper 1997, p. 210.

Ibid., p. 197.

Ibid., p. 220.

Unschuld, 1986, p. 3.

Unschuld, 1986, pp. 301, 387, 418, 516. 
Wang Shuhe 王叔和 (18O- c. 27O CE) is the author of the Maijing 脈經 (Pulse Classic), 2nd century CE. In this work, he echoes the tongue presentation in the Yin yang mai sihou, when he writes: 'A sick person with a curled tongue and retracted testicles is bound to die'. ${ }^{8}$ Wang uses the tongue presentation simply as a portent of impending death, indicating nothing about the type of illness contracted or organs involved in the demise. Against the copious writings on information discoverable about the inner body through the palpation of the pulse, we can see that tongue inspection was incidental in scholarly medicine of that time. The presentation of the tongue was noted with certain illnesses, certain vessel trajectories and certain prognosticatory patterns, but not as an indicator of problems within particular organs, and certainly not as a paramount piece of diagnostic information.

The Suwen recension of the Huangdineijing states that the physician who diagnoses using both the pulse and the complexion achieves perfection. ${ }^{9}$ While the physician's gaze was clearly valued during the Han, its focus was on complexion and the tongue hardly receives a mention.

The medical case history is a marvellous window into the actual practice of a physician at a given point in time. It offers the individual records of the diagnosis and treatment of a single patient by a single physician, though the content, context, and application of information may vary. ${ }^{10}$ One of the earliest examples of the case history can be found in the Shiji 史記 (Records of the [Grand] Historian) by Sima Qian 司馬遷, 2nd century BCE. A physician, Chunyu Yi 淳 于意, was summoned by imperial order to give an account of his practice. Offering 25 case histories in defence of his standing as a worthy physician, he writes that 'in every case where your vassal has conducted a medical consultation, he has always made a consultation record zhenji 針劑.'.1 A common turn of phrase is, 'when I examined the mai [pulse]....'2 Nowhere in these records do we find the comparable phrase, 'when I inspected the tongue'. Certainly, to Chunyu Yi, the tongue did not hold vital diagnostic information.

\section{Epidemics and the Search for Effective Treatment}

During the Song Dynasty (96o-1279), an onslaught of epidemics ravaged southern China. Treatments for these

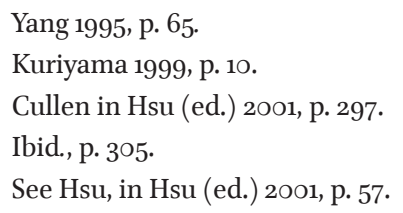

epidemic illnesses were too often unsuccessful, and the Imperial government was anxious to find ways to expand the scope of medical literature in the search for effective remedies.

It established a new bureau, Jiaozheng yishu ju 校正醫 書局 (Bureau for Revising Medical Texts), which it charged with searching out, revising and publishing a selection of ancient and previously neglected classics that might prove useful in combating epidemic illnesses. One of these rehabilitated texts was the Shanghan lun 傷寒論, ${ }^{13}$ written by Zhang Zhongjing 張仲景 (style name Zhang Ji 張機 $f$. late 2nd century $\mathrm{CE}$ ). Zhang is known to have compiled this text after an epidemic swept through his hometown of Changsha (in present-day Hunan province), killing numerous family members and decimating the general population. Over the next two centuries it became one of the most highly regarded and popularly disseminated medical texts. Its particular genius was to pay attention to the individual and evolving condition of each patient during a rapidly changing illness, not just to the fixed disease. ${ }^{14}$

While the Shanghan lun was revolutionary in its strategies for treatment with herbal prescriptions, it offers only scattered mentions of tongue presentation, and no tongue illustrations. One of these few mentions is in line 230 of the text. Under the rubric of 'Yangming illness', it lists a white tongue fur among indications for the use of the prescription Xiao chaihu tang 小柴胡湯 (Minor Bupleurum Decoction). Yet despite the paucity of tongue information in the text, this increased Song focus on treatments for febrile illnesses led to innovations during the following Jin-Yuan period (1115-1368 CE) which had major implications for the development of tongue diagnosis.

\section{Tongue Inspection Emerges as an Illustrated Diagnostic System}

The Jin-Yuan period saw the consolidation of power in the North of China, with concomitant cultural changes, such as the development of neo-Confucianism, in which old ideas were reworked. The current of widespread governmental, cultural and philosophical changes impacted upon medical thinking as well. One of four major medical innovators of the period was Liu Wansu 劉完素 (1110-1209). He put forward the hypothesis that the six pathogenic influences presented in the Suwen all ultimately manifest in a patient as fire. The prescriptions he developed and

13 See Goldschmidt 2009 for a discussion of the Song government's revision and promulgation of earlier medical texts.

14 Miyashita 1986, p. 112. 
his methods of treatment focused on ensuring that this fire did not accumulate within the body. His approach became known as the Cooling School. Another of the major innovators was Zhu Danxi 朱丹溪, who focused on the movement of 'ministerial fire' in the body. This could pose a risk to the Yin energy in the body, and specifically the Kidney's Yin. He founded the Nourishing Yin School. It becomes possible to imagine that with the reworking of the constraints around Shanghan theories of illness and the many manifestations of fire, there would be increasing interest in developing ways to 'see' and eventually depict pathogenic heat within the body.

Indeed, it is during the Yuan Dynasty, c. 126o CE that we find the first serious evidence of tongue inspection emerging as a system of diagnosis. A book entitled the Jinjing lu 金鏡錄 (Golden Mirror Record), authored by someone known only as Scholar Ao, presented 12 illustrations of tongues, relating them to the Cold Damage Disorders discussed in the Shanghan lun. We know of this lost text through another later text by Du Qingbi 杜凊碧. Du organised and supplemented the Jinjing lu, adding 24 of his own illustrations. The resulting work was published in 1341 as Aoshi shanghan jinjing lu. This text does indeed offer a system of what we would recognise today as tongue diagnosis. Du categorises colours of the body of the tongue, the tongue's shapes, the various peculiarities of surface geography, such as cracks and spots, and the different

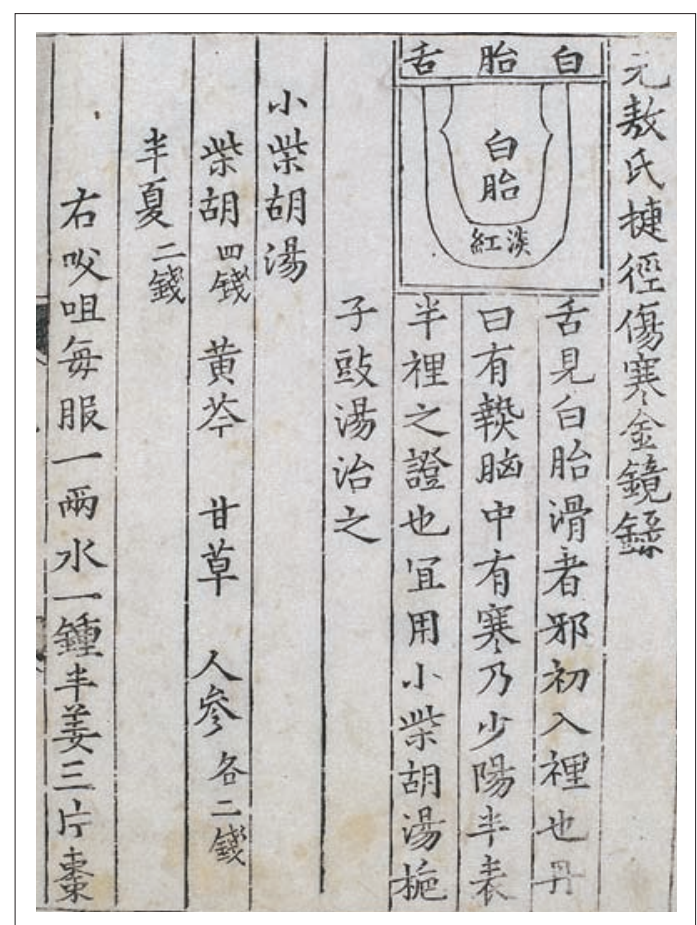

Figure 10.1 From 1341 edition of Aoshi shanghan jinjing lu, 敖氏傷寒 金鏡錄 showing Shaoyang presentation with a prescription for Xiao Chai Hu Tang, with dosage possibilities of tongue coatings. Importantly, he connects each illustration with a herbal prescription. Indeed, the Aoshi shanghan jinjing lu records the above-mentioned recipe for Xiao chaihu tang, (Minor Bupleurum Decoction) under Shaoyang 少陽 (Lesser Yang) illness - just as in the Shanghan lun - but additionally provides an illustration of the tongue one would see in a patient with this stage of illness, thereby facilitating diagnosis (Fig. 1).

The Aoshi shanghan jinjing lu appears to have been a much copied text. In the archives of the library of the China Academy of Chinese Medical Sciences (formerly China Academy of Traditional Chinese Medicine) there can be found an array of publications from the 14th century through to the 2oth century containing illustrations of the original 36 tongues presented by Du Qingbi. There are both woodblock prints (Fig. 2) and hand-drawn illustrations (Figs 3 , 4). Many of the woodblock prints are almost exact copies of the early text, but differences also occur. Some differ only slightly with variant titles of the individual illustrations or the sequencing of the drawings. Some compilations give basic black and white illustrations, while others - not necessarily newer ones - offer coloured illustrations. There are replications of the 36 tongues inserted into discussions of Shanghan illness, and compilations of tongue drawings that stand alone as discrete publications. Interestingly, some of the tongue texts include the prescriptions of the Jinjing lu, with and without dosages, and others simply

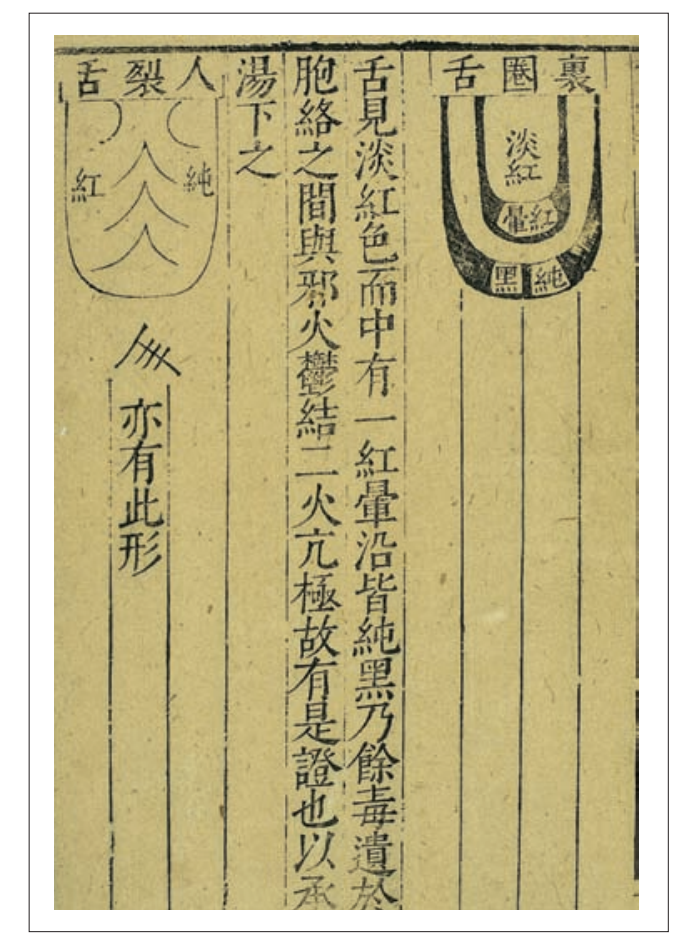

Figure 10.2 Shanghan zheng zhi zhun cheng (Standards of diagnosis and treatment for Cold Damage) Wang Kentang (Ming 1368-1644). $\odot$ Wellcome Library, London, Loo38014 


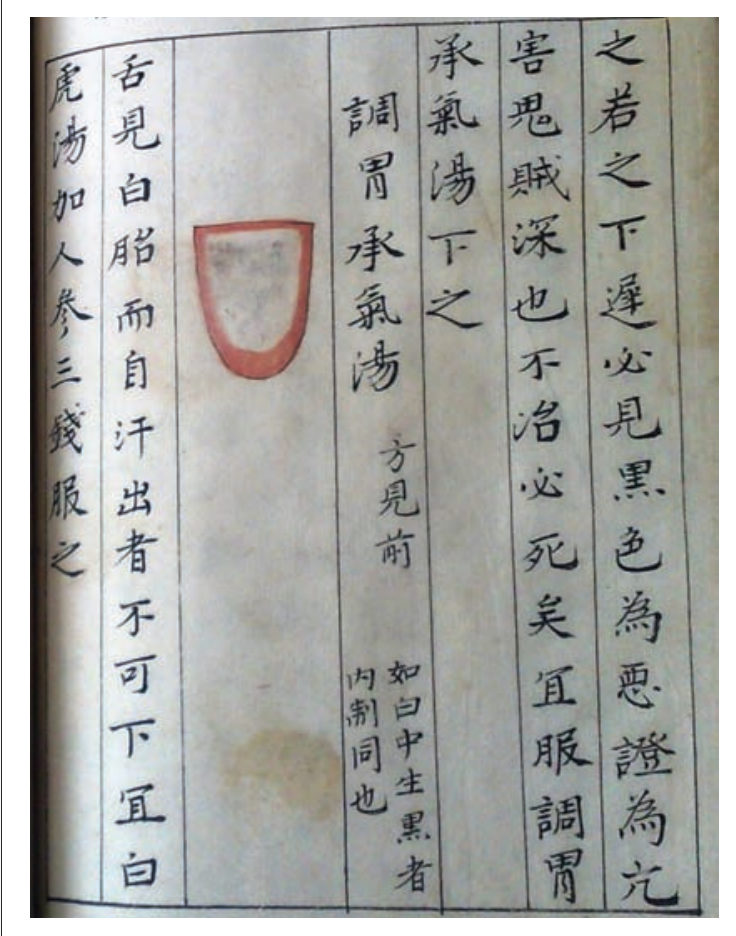

Figure 10.3 From a hand-drawn 1445 edition of the Shanghan jinjing lu 傷寒金鏡錄 tongue text. (C) The Library of the Academy of Chinese Medical Sciences

offer the illustrated tongues with a textual description. There are even handwritten texts which dispense with the drawings, having only numbered lists and descriptions of the 36 tongues, suggesting widespread familiarity. The existence of so many of these illustrated tongue texts, published over such a long period of time, highlights the importance they held for physicians, particularly in dealing with febrile illness.

\section{The Tongue's Rise to Prominence}

The taking of the pulse at the radial artery is arguably the most iconic diagnostic image of Chinese traditional medicine, with a great amount of textual history. The mastery of the pulse was an essential skill which traditional doctors achieved through years of practice. For literate doctors, this learning took place while practising as the disciple of another eminent physician, or was learned from the experienced elder physicians within a family network. However, during the Ming dynasty a combination of factors conspired against this usual accumulation of skill and expertise.

The numbers of scholars passing the imperial examinations in this period increased significantly, without an attendant increase in civil service posts. Trade however was on the rise, allowing the expanding and increasingly

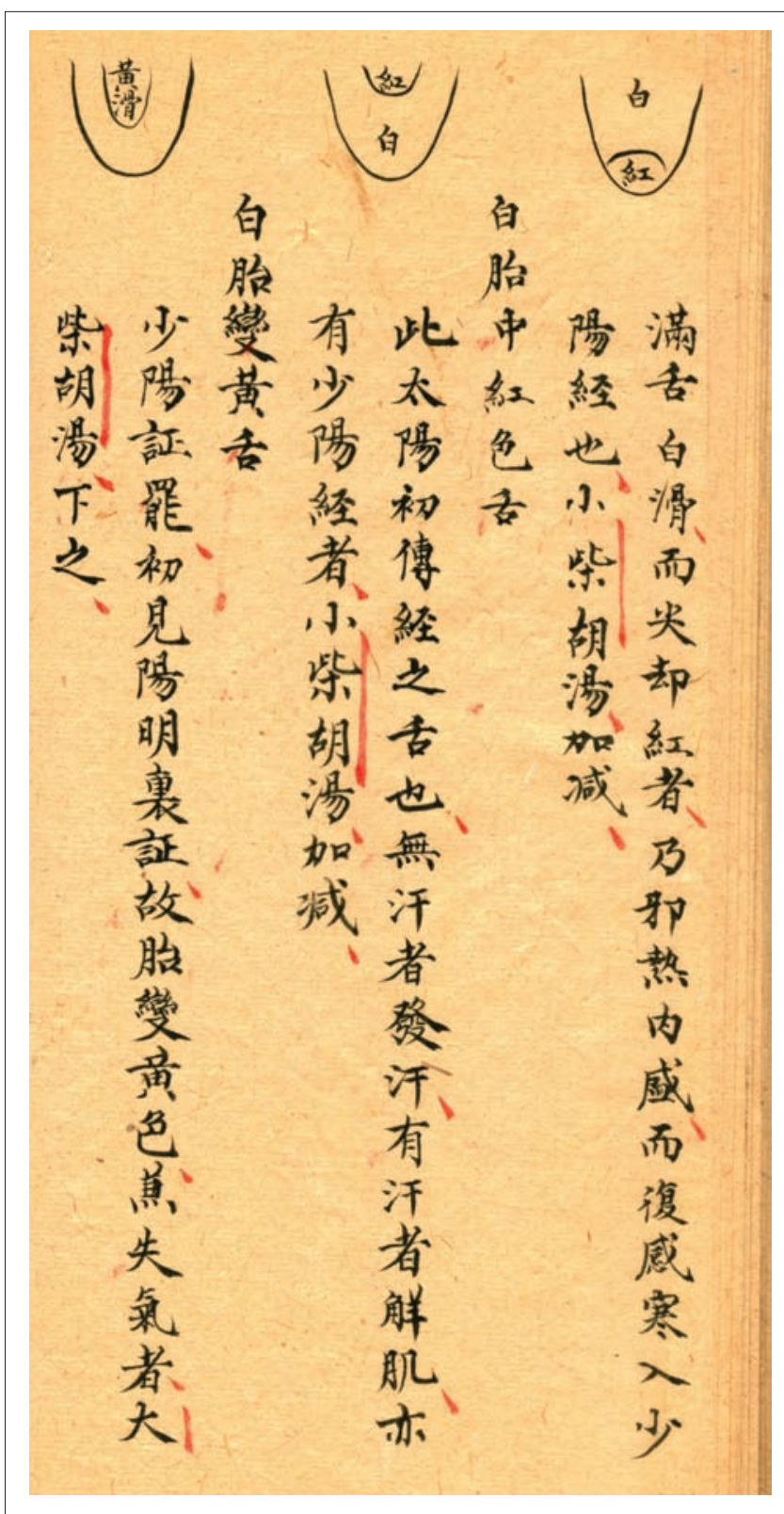

Figure 10.4 From Shebian sanshiliu zhong 舌辨三十六種, a 1910 hand-drawn text on tongues. Tongue on right showing the white coat and red tip with a prescription for Xiao Chai Hu Tang without dosage. (c) The Library of the China Academy of Chinese Medical Sciences

wealthy merchant class to finance the education of their sons. Additionally, advances in printing led to an unprecedented availability of texts. Medical texts were among the most desired, and the profession of medicine became an obvious choice for the scholarly gentry. This new rather sideways step from civil service post holder to respected physician had one significant obstacle. There was no sudden increase in scholar physicians available with whom to study. The mastery of medical theory did not always lead to clinical skill, and the new scholar-physicians were in need of assistance. 
Perhaps the tongue's rise to the diagnostic prominence it enjoys today had to do with its particular effectiveness in allowing a clear connection between the visual manifestion of a symptom of illness and the appropriate drug intervention in the treatment of that illness. Essentially, the tongue texts could be seen as a diagnostic shortcut.

The correct diagnosis, based upon the palpation of the pulse, might elude all but the most skilled physician. How different from diagnosis based upon the observation of the tongue, whose qualities are clear and easily categorised. A white, yellow or black coating cannot easily be confused with one other, nor can a pale tongue body be mistaken for a bright red one. Dryness or wetness, the presence or absence of fissures are among diagnostic qualities that can be clearly and objectively determined, whether by novice or skilled physician of long experience.

\section{Artistic Embellishment or Diagnostic Tool}

While discussing the emergence of the tongue images and the development of a system of tongue diagnosis, it is fundamental to note that these drawings were not merely decorative additions to a theoretical process. The drawings were themselves able to function as tools for diagnosis. In the 1341 text attributed to Du Qingbi, the first drawing is accompanied by text stating:

The tongue coat is slippery and white. It indicates the evil has just entered the body. The dantian 丹田 has heat, the chest has cold. This is Shaoyang, half outside, half inside. It is appropriate to use Xiao chaihu tang. ${ }^{15}$

The tongue image here gives the physician a representation of a tongue that could be expected to accompany a particular pattern of heat and cold lodged in the body, and which would impact upon certain channels and organs. In a sense, a cross reference.

Alongside the second drawing, however, we read:

The tongue's red colour indicates heat is amassing inside the body. You don't need to ask which channel. Whatever the channel, it is appropriate to use Touding qingshen san 透頂清神散.

Here is a clear and uncompromised statement that in some instances, the physician's subtle skills of pulse diagnosis, complexion diagnosis, channel and organ diagnostics, and theories of disease progression can all be set aside. All that is needed to treat some illnesses is the observation of a tongue matching the relevant image, and an appropriate herbal formula can be administered without doubt.

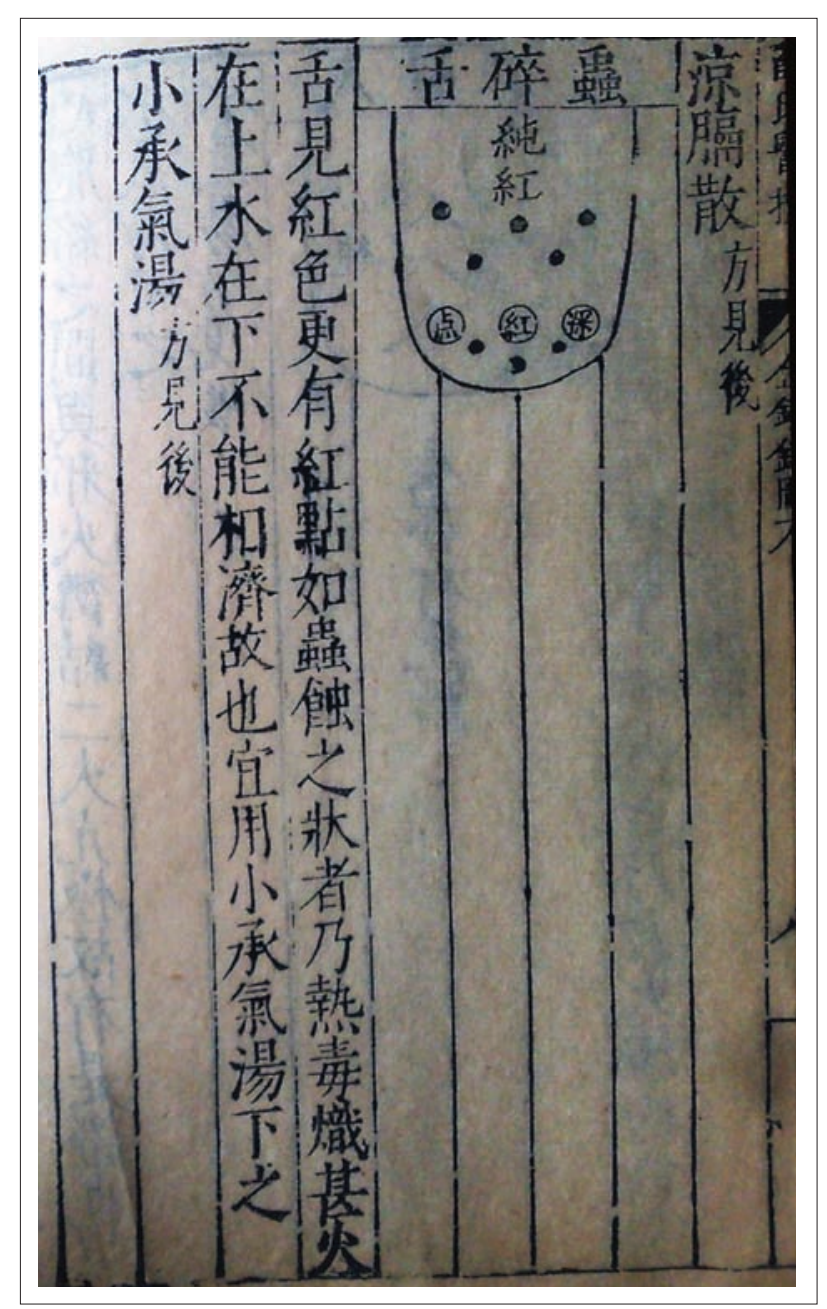

Figure 10.5 From the 1529 edition of Xue Ji's compilation of Waishang jinjing lu 外傷金鏡錄. @ Library of the Academy of Chinese Medical Sciences

\section{Tongue Texts become part of Medical Compilations}

During the Ming Dynasty (1368-1644), Xue Lizhai 薛立 齋 (style name Xue Ji 薛己, (1487-1559) contributed to the recognition and transmission of tongue diagnosis. In 1529 he authored a two-volume, 16-book compilation entitled Xue Shi yi'an 薛氏醫案 (Medical Case Records of Scholar Xue). One of the books in this collection was the Waishang jinjing lu, 外傷金鏡錄 (Golden Mirror Record of External Damage) (Fig. 5). In it he includes the 36 tongue illustrations of the Aoshi shanghan jinjing lu, along with a preface and an endnote extolling the importance of the tongues, and commentaries on them. The publication of this work and the prestige of its author undoubtedly did much to further the transmission of the tongue text.

The Ming was also a time in which case records developed as a distinct genre of medical writing. The advances in printing and the social and economic restructurings of Chinese society during the late Song and Ming facilitated 
the reproduction and dissemination of case records among physicians and the literate population. The compiling of case records became an intrinsic part of literate medical practice. ${ }^{16}$ An as yet cursory look at these records suggests that Ming physicians nearly always palpated the pulse, frequently observed the complexion and listened to the voice of a patient. The inspection of the tongue, however, doesn't yet appear to be a regular feature of diagnosis in the Ming, though it does occur occasionally.

\section{Proliferation of Tongue Texts during the Qing Dynasty}

The tongue diagnosis texts grew out of and at first accompanied the theories and prescriptions of the Shanghan lun, which posited a six-stage progression of illness in the body. Rather than rejecting this paradigm, physicians of the (late) Ming and Qing Dynasty expanded their bases for understanding the progression of disease. There were many innovative physicians, among them Wu Youke 吳又 可 ( $f l$. late 17th century), who wrote the Wenyi lun 温疫 論 (Treatise on Warm Heat). These physicians reworked ideas about the causation of febrile illness, implicating climatic pathogens and developing treatments that differed from the traditional Shanghan theories. Their work led to the development of a school of disease theory known as wenbing 溫病. ${ }^{17}$

During this time, there appeared an ever-increasing number of books discussing the tongue. Shen Douyuan's 申斗垣 ( $f$ l. early 17 th century) Shanghan guanshe xinfa 傷 寒觀舌心法 (Technique for Observing the Tongue in Cold Damage) weaves together existing tongue presentations associated with the six-stage progression of the Shanghan lun and the new wenbing theories. He is also the first to rank the colours of the body of the tongue, and emphasise the importance of the red tongue.

\section{Tongue Diagnosis becomes more Comprehensive}

But the diagnosis of the types and stages of febrile illness is only one aspect of the development of tongue inspection. Along with the proliferation of tongue texts and an increasing range of commentary, by the Qing Dynasty

16 For a discussion of the societal developments and stresses that impacted the practice of medicine in Ming China, see Hymes 1987 and Brokaw and Chow, 2005.

17 See Marta Hanson's investigation of the development of wenbing theory in Hanson 2011.

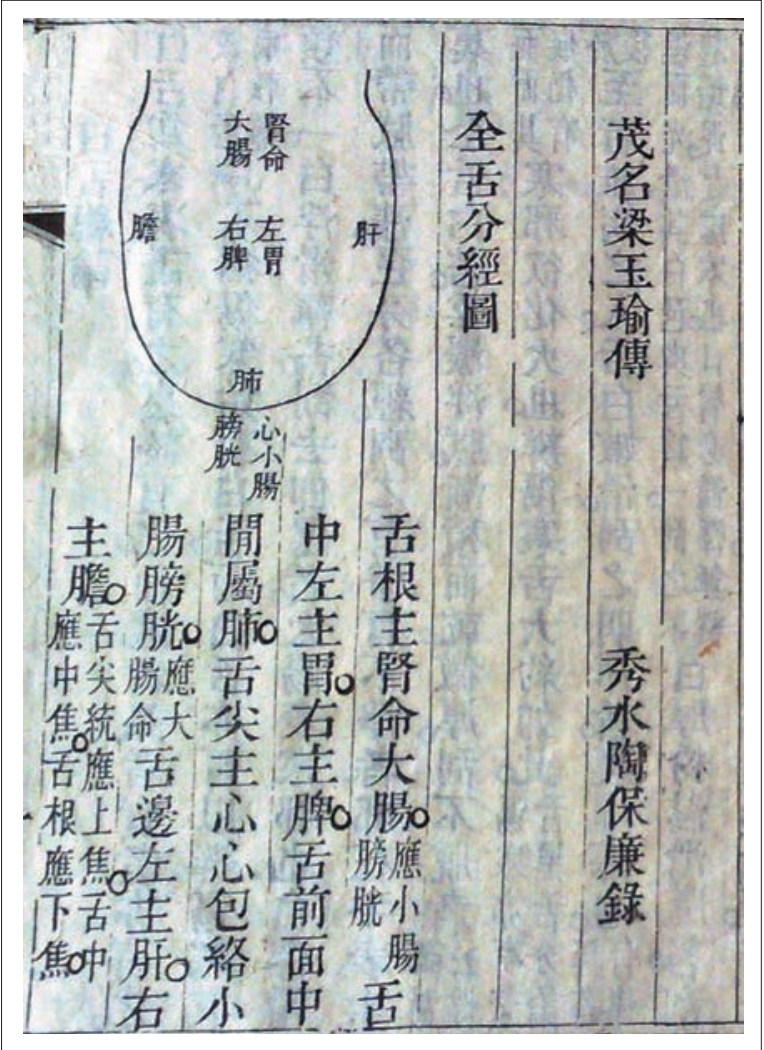

Figure 10.6 Qing Dynasty text Shejian bian zheng 舌鑑辨正, 1894, showing the mapping of internal organs on to specific areas of the tongue. (C) Library of the Academy of Chinese Medical Sciences

(1644-1911) tongue inspection and the images accompanying its discussion underwent two interesting changes. Firstly, the internal organs of the body were mapped onto the tongue. This allowed the entire framework of Chinese medicine's diagnostic theory to align with the presentation of a patient's tongue (Fig. 6).

As a direct result of this organ mapping, the entire framework of Chinese medicine's diagnostic theory could now align with the presentation of a patient's tongue. A vast range of bodily illnesses could be inferred from changes that were objectively observable on the tongue. The implications of this fact were enormous. Tongue diagnosis could be relevant not only for febrile illness, but for most conditions of 'unwellness'. Fissures on the surface geography of the tongue could not only identify dryness from fevers, but if located in the centre of the tongue could indicate a dearth of fluids or moisture in the stomach and a condition of Yin deficiency. Ulcerations on the edges of the tongue did not only appear with life threatening epidemics, but with types of internal 'heat' or 'fire', and demonstrated their impact on the functioning of the liver. Texts discussing the appearance of the tongue proliferated. 


\section{Western Medicine and the Constraint of Objectivity}

As physicians in China were reworking the diagnostic possibilities of tongue inspection in the Qing Dynasty, Western physicians were arriving in China in ever-increasing numbers and establishing an alternative medical culture and knowledge base. ${ }^{18}$ Put extremely simply, as Western military superiority eroded the power of the Chinese state, Western medicine's superiority benefited by association.

The 1910-11 pneumonic plague outbreak in Manchuria highlighted Western medicine's effective utilisation of isolation, quarantine, and cremation of victims' bodies to stem the contagion. ${ }^{19}$ The North Manchurian Plague Prevention Service was created in its wake, whose remit was to provide Western medical treatment, research and public health measures. For the Chinese government, the Service reflected a desire for international credibility and membership in the scientific community. Bridie Andrews cites a medical periodical in which He Bingyuan 何炳元, a prominent reformer of Chinese medicine, wrote:

Alas! The China of today is a sick nation weakened by injury and oppressed by noxious influences. How can we find someone to treat the nation, to eradicate the roots of the ailment and turn weakness into strength? Although we may wish to strengthen the nation, it is first necessary to strengthen the race. To strengthen the race it is first necessary to pay attention to hygiene. To do this, we must first understand physiology, and if we wish to understand physiology, we must first promote medicine. ${ }^{20}$

All of this suggests a time in which to lack 'modernity' and 'scientific skill and theory' was to be subjugated and inferior. By the end of the 19th and beginning of the 2oth centuries, Western medicine's entire identity was resoundingly modern, scientific, and redolent of superiority. Traditional medicine, on the other hand, was an unappealing art of waning prestige. Additionally, the new medicine arriving from Europe, Japan and America emphasised the importance of anatomical correctness and objectivity. The paradigm in which traditional medicine flourished had relatively little need for exact anatomy, and the primary diagnostic technique, pulse palpation, was an intensively subjective activity. But in traditional medicine's now valued pursuit of scientific respectability, the tongue offered possibilities.

18 There are myriad works on western expansion in China during the igth century. The role of medicine in these encounters is difficult to overstate.

19 For a description of the epidemic's containment, see Wu 2012.

$20 \quad$ Andrews 2014, p.94.
The images of tongues in medical texts that survive from the 14th century onwards display basic similarity. Whether hand-drawn, printed, black-and-white or coloured, they essentially comprise a U-shaped form with relevant colours, coatings, and surface geographies noted - in fact, the same sort of image that is used today by practitioners recording the qualities of a tongue in clinic notes.

But by the end of the 19th century and the beginning of the 2oth, the tongue images in Chinese medicine texts underwent a striking transformation.

The tongue was no longer a discrete site of observation; it was positioned anatomically. As shown below, the tongue was now sited within the skull, the cervical spine clearly defined. Salivary glands and upper-respiratory structures such as the larynx, pharynx and epiglottis figure prominently along with teeth and sinus cavities. In short, European traditions of anatomy had made an impact on Chinese medicine's tongue depictions.

Despite the fact that visualising the tongue with its 'lingual tonsil' or 'foramen caecum' offered no diagnostic advantage, anatomically correct illustrations were adopted in many tongue texts of Chinese medicine during the early 2oth century (Figs 7, 8, 9).

From the original 12 tongues to which Du Qingbi tells us he added an additional 24 , the illustrations in tongue texts have become increasingly numerous and detailed over the past two centuries. It is not uncommon for current texts to list 200 or more variations of tongues.

\section{Tongues and Technology}

Secure in its recent position as an objective and verifiable diagnostic tool (a red tongue is observably not black and a white coating neither yellow nor absent), tongue diagnosis lent itself happily to technological innovation. Beginning in the 1970s the humble photograph was used to make a true and objective record of a patient's tongue. Pictures of tongues have more recently been captured with digital imaging and analysed by computers.

In 2009, researchers in China asserted that an exact analysis of the tongue from digital pictures continues to be difficult. They recommend a further level of precision in which the tongue coating itself would be extracted from the digital photograph and further analysed. Such refinement in electronic management of tongue representations seek to create an objectively unassailable and automatic tongue imaging and diagnostic system.

Current students of Chinese traditional medicine are almost universally familiar with the standardised tongue image above (Fig. 6) of organ correlation and their clinical 

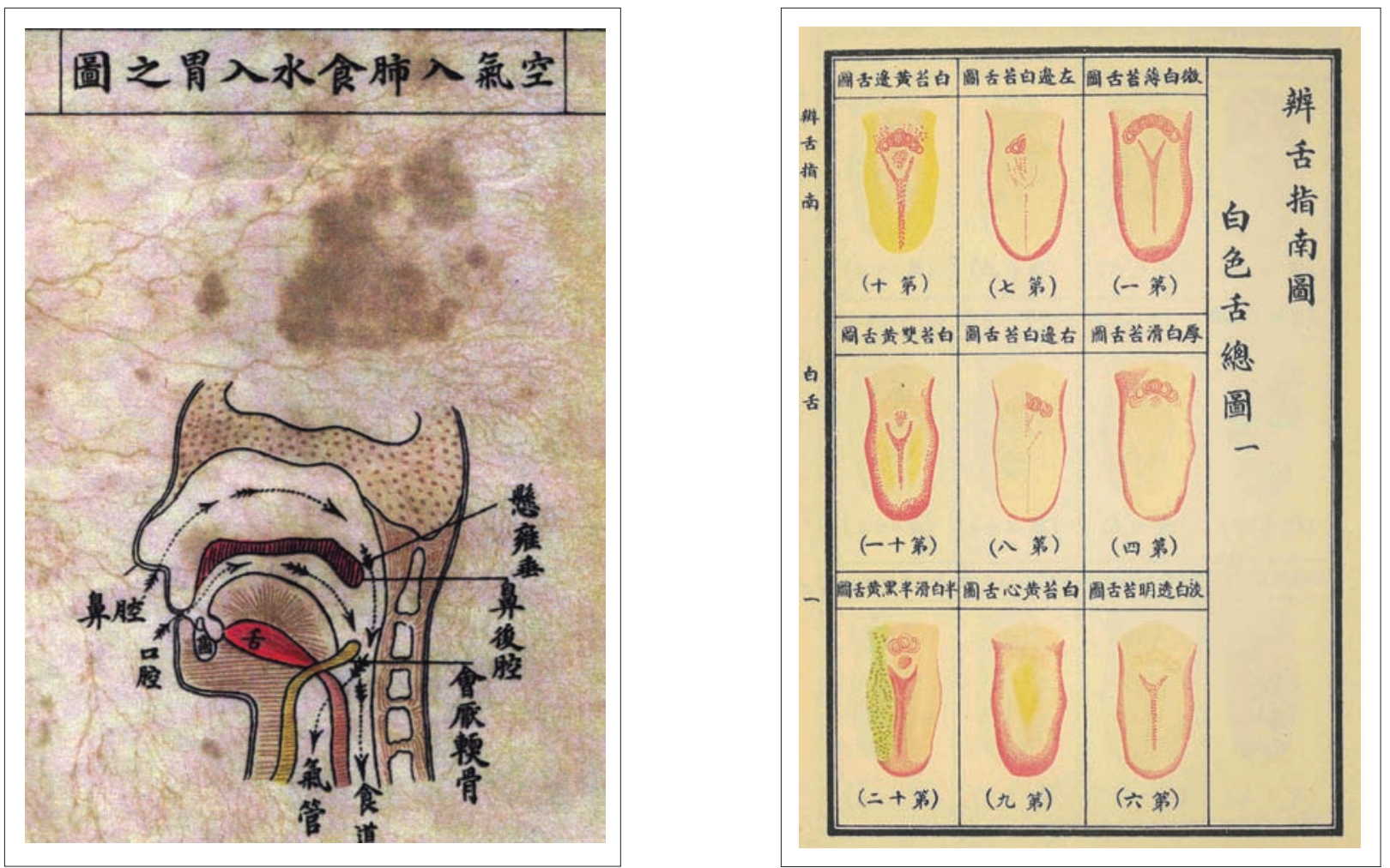

Figures 10.7 and 10.8 Bian she zhinan 辨舌指南, 1920. Figure 7 displays the anatomical placement of the tongue, while Figure 8, a summary of white coloured tongues, suggests a more anatomically correct rendering of the tongue surface, onto which the body's organs are mapped. Fig. 7: ( ) Library of the Academy of Chinese Medical Sciences; Fig. 8 @ Library of Needham Research Institute

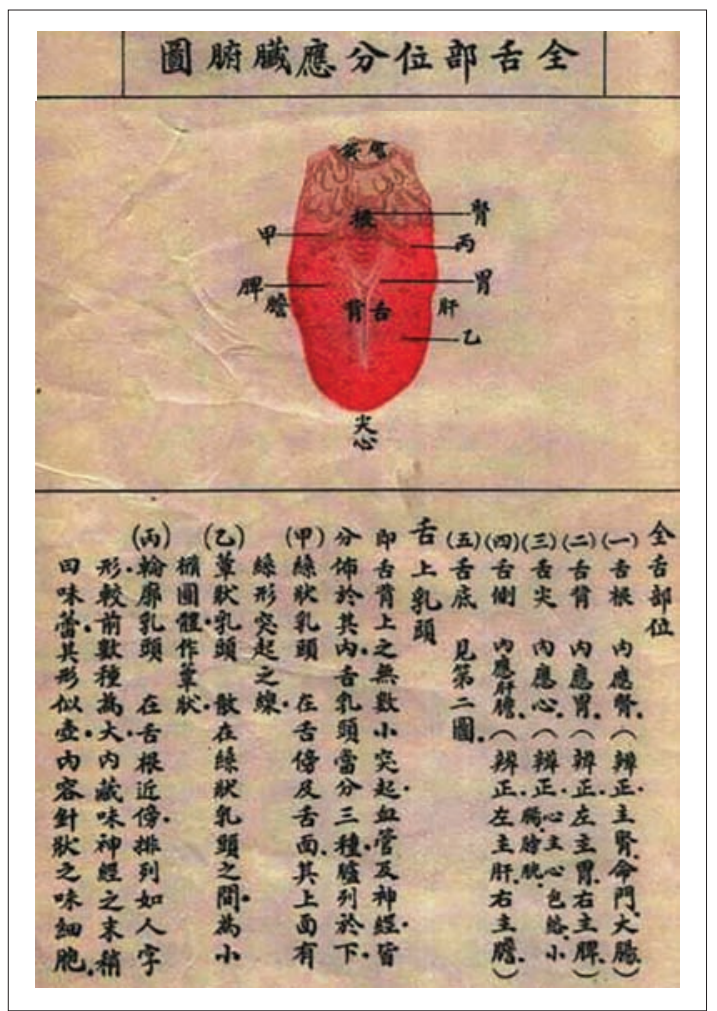

Figure 10.9 Bian she zhinan 辨舌指南, 1920. The body organs mapped onto the tongue. (C) The Library of the Academy of Chinese Medical Sciences notes are more likely than not to have the rudimentary U-shaped drawing with areas of diagnostic significance noted (Fig. 9). For practitioners who have moved from paper notes to computerised records, digital photographs of a patient's tongue are often utilised. In personal communications with various practitioners, I was told that the use of digital tongue photographs is attractive primarily because they are convenient to upload into computerised records, not because they are seen to offer any unique information. In these same conversations, the practitioners nearly always note that tongue diagnosis is easier to master than pulse diagnosis, and often serves as a fall-back technique if the pulse presentation is in doubt. When I described the electronic tongue imaging techniques being researched in China, Western practitioners of Chinese medicine reported finding the research interesting, but not something they were keen to know more about or could imagine using. As technology impacts upon traditional medicine, it is intriguing to consider what role the image of the tongue will play. 


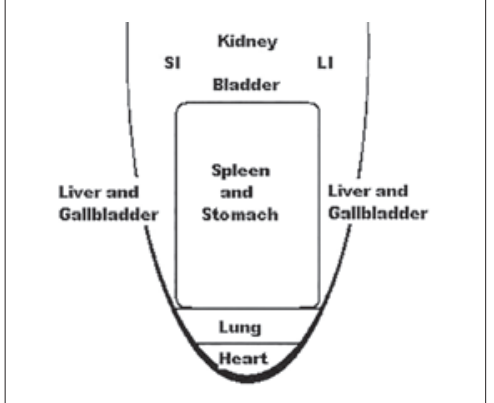

Figure 10.10 Standardised mapping of internal organs onto areas of the tongue, from student handouts. (C) The College of Integrated Chinese Medicine

\section{Conclusion}

Mention of the tongue in Chinese medical writings is seen and referenced as early as the Han Dynasty. A reference, however, is not a system of diagnosis. While a thread of interest in the tongue's appearance winds through the medical writings of early dynasties of China, it was in the Jin-Yuan era (12th-14th centuries) that the first specifically focused book on tongues appeared. It has been postulated that an antecedent to this early Jinjing lu text lies in Cheng Wuji's (1062-1155) Shanghan mingli lun 傷寒明理論, which describes coatings, colours and qualities to be seen on the tongue. ${ }^{21}$ But the marriage of tongue illustration with the required drug treatment was a ground-breaking innovation, which arrived in the form of the 36 tongues illustrated in the Aoshi shanghan jinjing lu.

During the Ming Dynasty, when scholar physician numbers were increasing rapidly, the ability of inexperienced physicians to secure a relatively scarce apprenticeship position was difficult. The tongue text, by then more easily reproduced and circulated, would have been immediately useful. The discourse among physicians focused more intensely on wenbing theories of disease during the Qing dynasty. The tongue's ability to reflect febrile conditions in the body led to increased focus and observation. By the late Ming and through the Qing Dynasty, the original 36 tongues images in the jinjing lu had expanded to include hundreds of distinct images.

The mapping of organs and channels onto the body of the tongue allowed the presentation of the tongue to be relevant to the entire theoretical framework of Chinese medicine. The usefulness of this particular innovation is difficult to underestimate. Students in colleges of Chinese medicine now had a diagnostic tool that was easier to learn

21 I owe the recognition of this precedent on tongue lore to Dr He Wei, who reported on a lecture by Zheng Jinsheng that she attended at the Academy of Chinese medicine in Beijing. than pulse palpation, and it had the additional recommendation of being observable and verifiable.

From the original extant 1341 edition of this visual diagnostic handbook to the automatic tongue image segmentation method now being researched in China, tongue images have played various innovative roles in the practice of Chinese medicine. Not the least of these has been to function as a diagnostic shortcut.

It is now more likely that a physician will observe a tongue to determine the more general state of the Qi, blood, fluids, Yin and Yang as they circulate in the channels and nourish the internal organs of the body rather than to decide specifically upon treatment in the case of febrile disease. Tongue inspection has become a foundation of diagnosis in Chinese medicine. Books with myriad digital photographs of tongues and the association of their appearance with varying symptoms of disease are commonplace. But the hand-drawn image has endured, to be found in the patient notes of generations of practitioners, still conveying relevant and useful clinical information upon which treatments are based.

\section{Bibliography}

\section{Primary Sources}

Aoshishanghanjinjing lu 敖氏傷寒金鏡錄 (Scholar Ao‘s Golden Mirror Record of Cold Damage) 1341, Du Qingbi 杜清壁; Edition 1529, Library of the China Academy of Chinese Medical Sciences, Beijing. Bian she zhinan 讋舌指南 1920, Cao Bingzhan 曹炳章.

Huangdi neijing lingshu 黃帝内經靈樞.

Huangdi neijing suwen 黃帝内經素問.

Huangdineijing taisu 黃帝内經太素 $c .610$, Yang Shangshan ed. 楊上善. Maijing 脈經, c. 280, Wang Shuhe 王叔和.

Shanghan mingli lun 傷寒明理論, 1156, Cheng Wuji 成無己.

Shanghan zhengzhi zhunshen 傷寒證治準繩, 1589, Wang Kentang, 王肯堂.

Shejian bianzheng 舌鑑辯正, 1897, Liang Yuyu 梁玉瑜. Xue shiyi'an 薛氏醫案, 1529 , Xue Ji 薛己.

\section{Secondary Sources}

Andrews, B. 1996, The Making of Modern Chinese Medicine, 1895-1937, Vancouver/Toronto: University of British Columbia Press.

2013, The Making of Modern Chinese Medicine, 1850-1960, Vancouver: University of British Columbia Press.

Bai, Linda Yunlu 白雲鹿, Shi Yundi 史雲迪, Wu Jia 吳佳, Zhang Yonghong 張永紅, Weng Weiliang 翁維良, Wu Yu 吳显, Bai Jing 白淨, 2009, 'Automatic extraction of tongue coatings from digital images: a traditional Chinese medicine diagnostic tool', Tsinghua Science and Technology 14.2 (April), 170-5.

Brokaw, C. and Chow, Kai Weng (eds), Painting and Book Culture in Late Imperial China, University of California Press, 2005

Cullen, C. 2001, 'Yi'an (case statements): the origins of a genre of Chinese medical literature', in Hsu (ed.), 297-323.

Goldschmidt, A. 2009, The Evolution of Chinese Medicine: Song Dynasty 960-1200, London: Routledge. 
Hanson, M. 2011, Speaking of Epidemics in Chinese Medicine: Disease and the Geographic Imagination in Late Imperial China, London: Routledge.

Harper, D. 1997, Early Chinese Medical Literature: The Mawangdui Medical Manuscripts, London/New York: Kegan Paul International.

Hsu, E. 1999, The Transmission of Chinese Medicine, Cambridge: CUP.

Hsu E. (ed.) 2001, Innovation in Chinese Medicine, Cambridge: CUP.

Hymes, R.P. 1987, 'Not quite gentlemen? Doctors in Sung and Yuan', Chinese Science 8, 9-76.

Kuriyama, Shigehisa, 1999, The Expressiveness of the Body, New York: Zone Books.
Miyashita, Saburo, 1986, A historical analysis of Chinese formularies and prescriptions: three examples, in Ogawa (ed.), 101-16.

Summers, W.C. 2012, The Great Manchurian Plague of 1910-1911: The Geopolitics of an Epidemic Disease, New Haven: Yale University Press.

Taizo Ogawa (ed.) 1986, History of Traditional Medicine, Proceedings of the 1st and 2nd International Symposia on the Comparative History of Medicine - East and West, Tokyo: Taniguchi Foundation.

Unschuld, P.U.1986, Nan-ching: The Classic of Difficult Issues, Berkeley/ Los Angeles: University of California Press.

Wang Shu-He (tr. Yang, Shou-Zhong) 1995, The Pulse Classic: A Translation of the MaiJing, Boulder: Blue Poppy Press.

Wu Liande 1959, Plague Fighter: The Autobiography of a Modern Chinese Physician, Cambridge: Heffer. 